\title{
THE "DESIRED" TEMPERATURE VALUE IN THE SELECTED AREA OF THE BODY IS THE MAIN CONDITION FOR THE EFFECTIVENESS OF DRUGS - Review Article
}

1,3A.L. Urakov*, ${ }^{2}$ N.A. Urakova and ${ }^{3}$ A.P. Stolyarenko

'Department of Modeling and Synthesis of Technological Structures Udmurt Federal Research Center of the Ural branch Russian Academy of Sciences, Izhevsk, Russia;

2Department of Obstetrics and Gynecology and ${ }^{3}$ Department of General and Clinical Pharmacology of the Izhevsk State Medical Academy of the Ministry of health Russian Federation - 426034

Email id: urakoval@live.ru

\begin{abstract}
It is shown that the Arrhenius law can become a vector of pharmacology development in the near future. In this regard, temperature pharmacology can become a new scientific and practical direction in which the local effect of medicines will be considered taking into account the value of the total and/or local temperature. It is demonstrated that the role of a catalyst in the development of temperature pharmacology can be played by infrared imaging using a thermal imager. It is expected that the result of the development of temperature pharmacology will be new fundamental principles that will allow consumers to adjust the effect of medicines by purposefully creating the "Useful" temperature in the selected area of the body. It is predicted that local use of drugs with, Heat or cold can increase the effectiveness and safety of treatment of diseases.
\end{abstract}

Key words: temperature pharmacology, local temperature, drugs, Arrhenius law. 


\section{INTRODUCTION}

Pharmacology is a very young natural science that studies the functional activity of living organisms and/or parts of their bodies, or individual organs in normal and pathological conditions after the introduction of biologically active substances. In this case, the studied biologically active substances are introduced into the body for general (resorptive) action and/or to a certain part of its body or to an organ for local action. Moreover, the effectiveness of each biologically active substance is studied, first of all, depending on its dose (usually in the range from "zero" to absolutely lethal dose) and concentration (also in the range from "zero" to cauterizing or necrotic concentration). The results obtained allow us to classify the studied substance by its biological activity and toxicity as food, drugs, or toxin (poison), or as irritating and cauterizing agent (respectively). ${ }^{1}$

The main achievements in the study of pharmacodynamics, pharmacokinetics of drugs, their dosage forms, application technologies, experimental and clinical trials have been obtained in the last 150 years. This began after professor Rudolf Buchheim proposed to investigate the mechanism of action of drugs in animal experiments. The fact is that March 1, 2020 marked the 200th anniversary of the birth of R.R. Buchheim (German: Rudolf Richard Buchheim, 1820-1879) - a German pharmacologist who since 1847 was a professor of pharmacology at the University of Dorpat (now Tartu) in Estonia, where he organized the world's first laboratory of experimental pharmacology. ${ }^{2}$
However, our knowledge of the effects of drugs on the human body is still incomplete and not absolute since all the concepts of pharmacology have not yet been fully formed. At the same time, the field of laboratory, experimental and clinical research is of great importance. Although most of the fundamental principles of basic sciences such as physics, chemistry, and mathematics have long been elucidated, a breakthrough in some of the fundamental foundations of pharmacology has yet to be made. The difficulties of pharmacology are caused by the fact that there are very large interferences in working with living beings, with their cells, subcellular organelles, as well as with molecules, especially with enzymes. These confusion are caused by their variability caused by cyclic and acyclic activity during life and even during the day. 3

Temperature is a very important and indisputable factor of many regularities for such fundamental sciences as physics, chemistry and biology. ${ }^{4}$ However, the value of the general and local temperature for the general and local action of drugs is still not enough has been studied. Temperature pharmacology is still not formed as part of general and private pharmacology. There are no recommendations about what is better in the reference books about medicines: to warm or cool the "sick" part of the human body, for the "treatment" of which a particular drug is used. At the same time, it has been shown that thermology is the basis of medicine since ancient times. ${ }^{5}$ In addition, the value of the General and local body temperature of a person has long been considered an important 
indicator of his health and adaptation to diseases, so the peculiarities of temperature dynamics in normal and pathological conditions are studied by students of medical faculties in all universities of the world. 6,7

Intensive progress in the field of biomedical thermology has occurred in recent years, as thermal imagers were created at this time and new methods of infrared diagnostics were developed. The progress of innovations in the field of biomedical thermology has greatly accelerated in recent years. This happened, on the one hand, due to the successful modernization of thermal imagers and their transformation into highly sensitive measuring devices for medical purposes, and on the other hand, due to the successful symbiosis of physiology and thermology, which allowed the development of new methods of infrared diagnostics. ${ }^{8}$ At the same time, a very important fact was established - the dynamics of local temperature of certain parts of the human body in normal (under natural conditions) it can be very intense and very significant. ${ }^{\text {In }}$ particular, it has been shown that the temperature of the fingers of a healthy adult can decrease from normal values to almost $0^{\circ} \mathrm{C}$ in just one minute on a frosty day.

At the same time, since the end of the 19th century, the Arrhenius law has been known in chemistry and biology, according to which an increase in temperature by 10 ${ }^{\circ} \mathrm{C}$ accelerates the rate of chemical reactions in an inanimate environment by an average of 2-4 times. 10 There is no doubt that the Arrhenius law also applies in a living environment. Moreover, the dependence of the speed of biochemical processes on the temperature in living tissues, organs and organisms is many times higher, since it depends very much on enzymes, whose activity can change 40 times when the temperature decreases or increases by $2-3$ ${ }^{\circ} \mathrm{C}$ from the normal value $\left(+37^{\circ} \mathrm{C}\right) .{ }^{11}$

At the same time, all textbooks and manuals on the treatment of human diseases indicate that in "normal" all people get sick the same way, namely, they become inflamed. It also indicates that the inflammation is manifested in patients by an increase in their body temperature. As an axiom, the following pattern is indicated, known since ancient times: the more dangerous the disease, the higher the patient's body temperature. Moreover, the group of the most dangerous diseases (then they were infections) was manifested by fever (and often even called this term). That's why people have always been interested in their body temperature. To do this, they usually put their hand to their forehead, since thermometers were not known until the early 18th. The fact is that mankind learned about the thermometer only in 1714, when it was invented by Gabriel Fahrenheit. ${ }^{2}$ Since then, thermometers are still used everywhere to diagnose diseases by body temperature in humans and all warm-blooded animals. The diagnosis of the disease is made when the body temperature exceeds normal values. Moreover, it is the lowering of body temperature to a normal value that is the coveted dream of all doctors in the treatment of most patients suffering from most diseases. It is no coincidence that anti-inflammatory drugs are the most popular in the world, and they remain the leaders in sales. This is paradoxical, but the 
description of the mechanism of their action is still based not on the value of the total body temperature, not on the value of the local temperature of the "sick" part of the body, and not on the Arrhenius law. There are still ongoing discussions about what is more correct, to lower or increase the body temperature for fever and what is needed to strengthen the treatment of diseases: take hot or cold baths, apply a hot water bottle or an ice pack ? However, everywhere it is clearly indicated that antiinflammatory drugs have an antiinflammatory and antipyretic effect and that they certainly "treat", since they have an antipyretic and anti-inflammatory effect!

However, even this seemingly fundamental position is currently being questioned. It has been proved that the local action of anti-inflammatory drugs often causes local hyperthermia and local inflammation, which in the oral mucosa and in the stomach wall can cause gingivitis, gastritis, and even ulcers. ${ }^{13,14}$ At the same time, according to Arrhenius ' law, local hypothermia can slow down and weaken, and local hyperthermia can accelerate and enhance of the local irritating and cauterizing effect of medications. But, unfortunately, in modern pharmacology, Arrhenius ' law is still not taken into account. Therefore, the value of hypo -, normo - and hyperthermia in the local and General action of "antipyretic" drugs for a long time remained secret information. And so until now, few people knew (despite the Arrhenius law) what is "necessary" to do for the treatment of diseases: a hot water bottle (hot water) or an ice bubble (cold water). At the same time, it was considered correct to store medicines in cold conditions and inject them into the human body cold (at a temperature of drugs below normal human body temperature). Few people have thought about the importance of local hypothermia for the mechanism of action of drugs, which is created by drugs on the way to their introduction into the patient's body "in the ignorance" of doctors. But now the situation has changed dramatically due to the widespread introduction of thermal imagers in medicine and in everyday life. Thanks to these devices, humanity is rapidly seeing the light and many "secret" information about the local interaction of drugs in Hypo -, normo and hyperthermia become well-known, and some of them are rapidly being implemented in practice in the form of innovations and successfully displace what for hundreds of years was considered the unshakeable norm. ${ }^{15}$

\section{Conclusion}

Thus, it may well happen that very soon progress in pharmacology will occur along the vector that was set by the great Arrhenius, that is, the effect of drugs will be corrected (enhanced or weakened) by purposefully creating the "right" temperature (general and/or local) in the selected area of the body. And then the "correct" temperature value in the selected part of the human body will become one of the easily changeable and manageable factors for improving the effectiveness and safety of medicines. 


\section{REFERENCES}

Peper A. Aspects of the relationship between drug dose and drug effect. Dose Response. 2009; 7(2): 172-192. doi: 10.2203/dose-response.08-019.Peper

Reznikov K.M. Pharmacological vector of Rudolf Buchheim. Research Results in Pharmacology. 2019; 5(1): 103-116. https://doi.org/10.3897/rrpharmacology.5.32 234.

Brown J.B. Types of ovarian activity in women and their significance: the continuum (a reinterpretation of early findings)Hum Reprod Update. 2011; 17(2): 141-158. doi: 10.1093/humupd/dmq040.

Urakov A.L. Development of new materials and structures based on managed physicalchemical factors of local interaction. IOP Conf. Ser.: Mater. Sci. Eng. 2016. V. 123. 012008. doi:10.1088/1757$899 X / 123 / 1 / 012008$.

Urakov A.L. Thermology is the basis of medicine since ancient times. Thermology International. 2017. V. 27. N 2. P. 78-79.

Johnson J.M., Kellogg D.L. Local thermal control of the human cutaneous circulation. J Appl Physiol (1985). 2010; 109(4): 12291238. doi: 10.1 152/japplphysiol.00407.2010.

Tansey E.A., Roe S.M., Johnson C.J. The sympathetic release test: a test used to assess thermoregulation and autonomic control of blood flow. Adv Physiol Educ. 2014:38(1):87-92.

doi
Urakov A.L., Ammer K., Urakova N.A., Chernova L.V., Fisher E.L. Infrared thermography can discriminate the cause of skin discolourations. Thermology international. 2015. Vol. 25. N. 4. P. 209 - 215.

Urakov A.L., Ammer K., Dementiev V.B., Urakova N.A., Gadelshina A.A. The contribution of Infrared Imaging to designing a "winter rifle" - An observation study. Thermology international. 2019; 29(1): $40-46$.

Logan S.R. The origin and status of the Arrhenius equation. J. Chem. Educ. 1982; 59 (4): 279-281. https://doi.org/10.1021/ed059p279.

Alberts B., Johnson A., Lewis J., Morgan D., Raff M., Roberts K., Walter P. Molecular Biology of the Cell. 6th edition. 2014: 1464.

King A. L. Thermophysics. (Books in Physics). Published by W.H. Freeman, San Francisco. 1962: 369.

Urakov A.L., Urakova N.A., Lovtsova L.V., Sorokina Yu.A., Zanozina O.V. Osmotic activity and safety of non-steroidal antiinflammatory drugs in injection medicinal forms. Eksperimental'naya i Klinicheskaya Farmakologiya. 2018; 81 (10): 15-19.

Urakov A., Urakova N., Reshetnikov A., Kopylov M., Kasatkin A., Baymurzin D., Gabdrafikov R. The facts that the physicalchemical properties of modern tablets distinguish them from natural food lumps. IOP Conf. Series: Materials Science and Engineering. 2017; 175: 012012. doi:10.1088/1757-899X/175/1/012012.

10.1152/advan.00095.2013. 
Urakov A.L., Kasatkin A.A., Urakova N.A., in phlebography. Journal of Pharmacology Urakova T.V. Cold sodium chloride solution and Pharmacotherapeutics. 2016. V. 7. (3). $0.9 \%$ and infrared thermography can be an alternative to radiopaque contrast agents P. 138 - 139. doi: 10.4103/0976-500X.189675. 